Pediat. Res. 7: 826-831 (1973)

Anencephaly fetus estradiol placenta

estrone

\title{
Unconjugated Estrogens in the Perinatal Period
}

\author{
Frederia M. Kenny, ${ }^{[33]}$ Kitti Angsusingha, Dora Stinson, and Julane Hotchiss \\ Departments of Pediatrics and Physiology, University of Pittsburgh School of Medicine, and the Children's Hospital \\ of Pittsburgh, Pittsburgh, Pennsylvania, USA
}

Extract

High levels of unconjugated estrone (( $\left.\mathrm{E}_{1}\right)$ 3-hydroxyestra-1,3,5(10)-triene-17-one) and estradiol $\left(\left(\mathrm{E}_{2}\right)\right.$ estra-1,3,5(10)-triene-3,17 $\beta$-diol $)$ were found at term in maternal venous, umbilical vein, and umbilical artery plasma. For estrone the respective values in nanograms per milliliter \pm SD were $12.8 \pm 5.9,25.1 \pm 6.5$, and $13.2 \pm 7.7$. For estradiol the respective values were $17.3 \pm 9.2,8.1 \pm 4.0$, and 5.1 \pm 3.2 . For estrone, levels for umbilical vein were higher than those in the paired maternal and umbilical artery; estradiol was higher in maternal vein than in the paired umbilical vessels. Absence of the fetal adrenals was associated with low levels of estrone and estradiol for maternal and umbilical vessels, whereas, in anencephaly, only the maternal levels were markedly diminished. An initially rapid, and then a slower decline in both estrogens was found in normal infants during the first $72 \mathrm{hr}$ of life.

\section{Speculation}

Despite extensive metabolism of unconjugated estrogen by the fetus, umbilical arterial levels of estrone and estradiol are high. Nevertheless, the neonate shows scant clinical evidence of those high levels. This could be due to incomplete development of estrogen receptors in target tissues, plasma protein binding of estrogen, competition between the biologically most potent estrogen estradiol and the less potent estrone and estriol $\left(\left(\mathrm{E}_{3}\right)\right.$ estra-1 $, 3,5(10)$-triene-3,16 $\alpha, 17 \beta$-triol $)$, or other factors.

\section{Introduction}

The metabolism of estrogens in the fetoplacental unit has been explored extensively at midterm gestation and was the subject of recent reviews $[2,5]$. Less attention has been directed to estrogen metabolism at term, due in part to inability to manipulate the experimental subjects at that time, and in part to the large amounts of serum or plasma previously needed for the laborious methods for estrogen quantitation by classic techniques.

The advent of radioimmunoassay for quantitation of circulating estrogens makes it possible to ask new questions regarding estrogen metabolism at term and in the perinatal period.
The questions posed in this investigation were as follows. (1) What are the levels of unconjugated estrone and estradiol to which the term fetus is exposed, and to what extent does he diminish the level of unconjugated estrogens? (2) How do these levels relate to those of the mother?

\section{Methods}

Plasma estrogen levels were determined by a modification of the method described by Hotchkiss et al. (10) utilizing Sephadex LH-20 chromatography for the isolation of estrone and estradiol. In brief, this chromatographic step consists of application of the residue of diethyl ether extracts of 5-1,000 $\mu 1$ serum to Sephadex 
Table I. Estrogens produced by fetoplacental unit tested for cross-reactivity with antibody

\begin{tabular}{cc}
\hline Steroids tested & Estradiol equivalent, $\mathrm{ng}^{1}$ \\
\hline 2Methoxyestrone & 0.007 \\
$6 \alpha$-OH-estradiol & 0.015 \\
$15 \alpha$-OH-estrone & 0.007 \\
$15 \alpha-\mathrm{OH}$-estradiol & 0.07 \\
$16 \alpha-\mathrm{OH}$-estradiol & 0.02 \\
$16 \mathrm{~K}$ eto-estradiol & 1.0
\end{tabular}

1 Ten nanograms of each steroid were used; equivalent in terms of estradiol.

LH-20 columns $(0.5 \times 6.5 \mathrm{~cm})$ previously equilibrated with the eluting solvent mixture (heptane-chloroformmethanol-water, 10/10/1.5/0.06). Chromatography of ${ }^{14} \mathrm{C}$-labeled steroids showed that estrone emerged from the column in the 1.3-3.3-ml fraction, whereas estradiol emerged in the $4.3-8.3-\mathrm{ml}$ fraction. The columns, used repeatedly for 6 months, were stored immersed in column solvent in a closed glass container when not in use, and were recalibrated monthly using ${ }^{14} \mathrm{C}$-labeled estrogens.

This chromatographic step isolates and removes some of the compounds known to cross-react weakly with this antiserum [10], as cholesterol emerges in the first milliliter of the eluate, and estriol emerges considerably later than estradiol. Additional estrogens produced by the fetoplacental unit were tested for crossreactivity with the antiserum (Table I). While 16-keto estradiol caused significant displacement of tritiated estradiol from the antiserum, it would not contribute reactive material to the radioimmunoassay of estrone and estradiol inasmuch as it emerges from the column after estradiol.

Triplicate standard curves for estrone and estradiol $(5-100 \mathrm{pg})$ were prepared in disposable glass culture tubes $(12 \times 75 \mathrm{~mm})$ in which 2 or $4 \mathrm{ml}$, respectively, of column solvent had previously been evaporated.

An antiserum to $17 \beta$-estradiol-succinyl-bovine serum albumin raised in ewes was kindly supplied by Drs. Ferin and Vande Wiele [7].

The radioimmunoassay was performed by the sequential addition of $100 \mu \mathrm{l}$ estrogen antiserum (diluted $1 / 135,000$ for the estrone assay and $1 / 180,000$ for the estradiol assay) followed $30 \mathrm{~min}$ later by the addition of $100 \mu \mathrm{l}$ of a tritiated estrone solution $\left(2,4,6,7{ }^{3} \mathrm{H}\right.$-estrone, spec act $95 \mathrm{Ci} / \mathrm{mm}$ [26], ca. 10,000 cpm in $0.01 \mathrm{~m}$ phosphate buffered saline containing $0.1 \%$ gelatin). After overnight incubation of the samples at $4^{\circ}$, separation of the antibody-bound and free steroid was performed as previously described (10). The antibody- bound steroid was decanted into scintillation vials to which $10 \mathrm{ml}$ toluene-based scintillation medium $(7 \mathrm{~g}$ 2,5-diphenyloxazole [27] and $0.3 \mathrm{~g}$ p-bis $(O$-methylstyryl)benzene [26] per liter toluene) were added.

The capped samples were shaken for $1 \mathrm{hr}$ to ensure extraction of the radioactive steroid from the aqueous into the organic phase, and counted in a Packard model 3320 liquid scintillation spectrometer [27] with a tritium counting efficiency of $50-55 \%$.

\section{Blanks}

Blank values determined by the extraction, chromatography, and radioimmunoassay of $20-1,000-\mu l$ aliquots of water ranged between 0.7 and $3.6 \mathrm{pg}$ for estrone, and 1.6 and $6.0 \mathrm{pg}$ for estradiol.

\section{Duplicates}

All sera were assayed in duplicate, and all samples from an individual mother-infant pair were performed within the same assay. The intra-assay coefficient of variation for $36 \mathrm{pg}$ estrone was $6.3 \%$; for $38 \mathrm{pg}$ estradiol the figure was $6.6 \%(n=10)$. Inter-assay coefficients of variation for $61 \mathrm{pg}$ estrone were $6.6 \%$, and for 26 pg estradiol were $9.4 \%$, respectively $(n=9)$.

\section{Recoveries}

In each assay, duplicate 50-pg amounts of both estrone and estradiol added to $20-1,000-\mu 1$ aliquots of water were carried through the extraction, chromatography, and radioimmunoassay steps to determine procedural losses. The average recovery of estrone was $80 \%$, and of estradiol was $83 \%$. The mean difference in percentage of recovery between duplicates within a given assay was $6 \%$ for both estrogens with a range of $1-11 \%(n=10)$.

\section{Calculations}

The standard curves for both estrone and estradiol were linearized using the logit transformation described by Rodbard (21). The amount of material in the sample was read from the standard curve, the appropriate blank value subtracted, and the result corrected for procedural losses as determined in duplicate for each assay. The final data are expressed as picograms or nanograms of steroid per milliliter of serum.

\section{Experimental Subjects}

In the studies performed at delivery, maternal venous plasma was obtained within 5 min before birth from the antecubital vein, and umbilical artery and vein 
Table II. Unconjugated estrone and estradiol in paired maternal and umbilical vessel plasma ${ }^{1}$

\begin{tabular}{|c|c|c|c|c|c|c|c|c|c|}
\hline \multicolumn{4}{|c|}{ Normal subjects } & \multicolumn{3}{|c|}{ Estrone, $\mathrm{ng} / \mathrm{ml}$} & \multicolumn{3}{|c|}{ Estradiol, ng/ml } \\
\hline \multirow{2}{*}{ Initials } & \multirow{2}{*}{ Sex } & \multirow{2}{*}{$\begin{array}{l}\text { Gestational } \\
\text { age, mo }\end{array}$} & \multirow{2}{*}{$\begin{array}{l}\text { Birth weight, } \\
\quad \mathrm{Kg}\end{array}$} & \multirow{2}{*}{ Maternal vein } & \multicolumn{2}{|c|}{ Umbilical } & \multirow{2}{*}{$\begin{array}{c}\text { Maternal } \\
\text { vein }\end{array}$} & \multicolumn{2}{|c|}{ Umbilical } \\
\hline & & & & & Vein & Artery & & Vein & Artery \\
\hline $\mathrm{CH}$ & $\mathrm{M}$ & 38.3 & 2.9 & 4.3 & 23.7 & 4.7 & 7.4 & 5.9 & 1.9 \\
\hline$D A$ & $\mathrm{~F}$ & 41.6 & 3.6 & 7.5 & 26.3 & 7.6 & 9.2 & 6.7 & 2.0 \\
\hline$D I$ & $\mathrm{~F}$ & 40.0 & 3.2 & 16.4 & 28.4 & 26.7 & 14.7 & 4.8 & 7.9 \\
\hline$M O$ & $\mathrm{~F}$ & 42.1 & 3.7 & 3.6 & $\underline{15.5}$ & 5.4 & 15.4 & 2.3 & $\underline{1.8}$ \\
\hline$R A$ & $\mathrm{~F}$ & 41.3 & 3.5 & $1 \overrightarrow{6.9}$ & $\overline{16.0}$ & 4.9 & 10.9 & $\overline{8.4}$ & $\overline{2.5}$ \\
\hline$R O$ & $F$ & 37.7 & 2.7 & 18.5 & 38.7 & $1 \overline{5.5}$ & 6.9 & 13.1 & 4.4 \\
\hline$R U$ & $F$ & 40.3 & 3.6 & 11.8 & $\overline{26.1}$ & 24.2 & $3 \overline{1.9}$ & 5.5 & 9.4 \\
\hline$S A$ & $\mathrm{~F}$ & 37.1 & 3.4 & 20.5 & 27.1 & 13.8 & $\overrightarrow{30.6}$ & 9.9 & 4.6 \\
\hline$T E$ & $\mathrm{~F}$ & 41.4 & 3.9 & $\overline{9.7}$ & 28.9 & 19.1 & 28.6 & 16.7 & 4.9 \\
\hline$W I$ & $\mathrm{M}$ & 40.0 & 3.6 & 18.5 & 20.1 & 9.9 & 17.5 & $\overline{7.4}$ & 11.3 \\
\hline $\bar{X}$ & & & & 12.77 & 25.08 & 13.18 & 17.31 & 8.07 & 5.07 \\
\hline SEM & & & & 1.97 & 2.16 & 2.56 & 3.06 & 1.34 & 1.07 \\
\hline SD & & & & 5.91 & 6.47 & 7.67 & 9.17 & 4.01 & 3.21 \\
\hline$A R^{2}$ & $\mathrm{~F}$ & 45 & 2.9 & 1.9 & 20.8 & 8.9 & 3.0 & 6.2 & 3.2 \\
\hline$T H^{3}$ & $\mathrm{M}$ & 39.3 & 3.3 & 2.9 & 6.6 & 3.2 & 5.5 & 3.3 & 1.7 \\
\hline
\end{tabular}

${ }^{1}$ The highest and lowest values in each column are underlined.

${ }^{2}$ Anencephaly.

${ }^{3}$ Absent adrenals.

plasma from a section of umbilical cord clamped above and below the site to be sampled. Cord clamping occurred 1-2 min after the infants' heel left the perineum. All infants had uncomplicated vaginal deliverics. Specimens were obtained from neonates by heel prick and collected in capillary tubes. Informed consent was obtained from each parent before initiation of each study.

The anencephalic at autopsy had a well developed pituitary, and the adrenal glands weighed $1 \mathrm{~g}$ (combined weight).

The male infant with presumed absence of adrenals had three previous brothers who died between 1-3 days of age. Of two who were autopsied, a careful search was made for adrenal tissue and none was found. Our patient had poor circulation at birth, with circulatory collapse at age $2 \mathrm{hr}$, which responded to glucocorticoid therapy. Cord and ammotic fluid cortisol 1.3 and $1.4 \mu \mathrm{g} / 100 \mathrm{ml}$, respectively, and corticosterone sulfate levels of 0.1 and $0.4 \mu \mathrm{g} / 100 \mathrm{ml}$, respectively, kindly determined by Drs. Claude Giroud and George Klein (14), were low. The normal mean values for cortisol are 8.6 and $1.8 \mu \mathrm{g} / 100 \mathrm{ml}$ in cord blood and ammiotic fluid, respectively; for corticosterone sulfate those values are 4.4 and $4.8 \mu \mathrm{g} / 100 \mathrm{ml}$. Further details of this patient are in press (19).

\section{Results}

Studies at term (Table II) indicated that, for unconjugated estrone, umbilical vein levels were always greater than those of the corresponding umbilical artery. In 9 of 10 cases, the umbilical vein levels exceeded those of the maternal vein. The mean value for umbilical vein $\mathrm{E}_{1}$ was approximately double the value for maternal vein and umbilical artery. Paired comparisons showed umbilical vein to exceed maternal vein $(P<0.001)$ or umbilical artery $(P<0.0005)$.

However, for estradiol, maternal venous levels exceeded those of the corresponding umbilical vein in nine instances. In 7 of 10 subjects, the umbilical vein estradiol exceeded the umbilical artery value. The mean value for maternal unconjugated $\mathrm{E}_{2}$ was double that found in umbilical vein, the latter being 1.6 times greater than that in the umbilical artery. Paired comparisons showed maternal vein to exceed umbilical vein $(P<0.025)$ and umbilical artery $(P<0.005)$.

Maternal venous levels of estrone and estradiol in one subject bearing an anencephalic infant $(A R)$ and in one subject bearing an infant with presumed adrenal absence were lower than the lowest value observed in the normal maternal group.

In contrast, however, umbilical venous and arterial 
Table III. Plasma levels of estrone and estradiol during first 72 hr of life

\begin{tabular}{lrrrrr}
\hline & \multicolumn{5}{c}{ Steroid levels at various ages, pg/ml } \\
\cline { 2 - 6 } & $2 \mathrm{hr}$ & $12 \mathrm{hr}$ & $24 \mathrm{hr}$ & $48 \mathrm{hr}$ & $72 \mathrm{hr}$ \\
\hline Estrone & 1,100 & 280 & 150 & 75 & 50 \\
Mean & 200 & 65 & 25 & 15 & 10 \\
SEM & 4 & 4 & 9 & 7 & 6 \\
Number & & & & & \\
Estradiol & 370 & 85 & 70 & 40 & 30 \\
Mean & 20 & 20 & 20 & 10 & 10 \\
SEM & 3 & 4 & 10 & 8 & 7 \\
Number & & & & &
\end{tabular}

levels of estrone and estradiol appeared to be normal in the anencephalic infant $(A R)$, whereas these steroid levels were notably lower in the infant with presumed adrenal absence $(T H)$. The lowest values observed for the group of normal infant umbilical vessel samples were higher than those observed for infant $T H$.

$$
\begin{gathered}
\text { Studies in Infants between Birth } \\
\text { and Age } 3 \text { Days }
\end{gathered}
$$

Disappearance Rate of $E_{1}$ and $E_{2}$ (See also Table III)

Initially there was a very rapid decline in the levels of unconjugated $\mathrm{E}_{1}$ and $\mathrm{E}_{2}$, followed by a more gradual fall. Considering only the portion of the slopes between 24 and $72 \mathrm{hr}$ of age, the times required for a $50 \%$ decrease in the values for $\mathrm{E}_{1}$ and $\mathrm{E}_{2}$ were approximately 30 and $38 \mathrm{hr}$, respectively.

\section{Discussion}

Diczfalusy [5] and others have shown that the midterm fetus makes an important contribution to the increased production of estrogens during pregnancy by providing precursors, especially $3 \beta$-hydroxyandrost-5en-17-one sulfate (dehydroepiandrosterone sulfate (DHAS)) and 16 $\alpha$-hydroxyandrost-5-en-17-one (16 $\alpha$ OH-DHA [28]) for placental aromatization and conversion to $\mathrm{E}_{1}, \mathrm{E}_{2}$ and $\mathrm{E}_{3}[2,5]$. The fetus has an extensive capacity to conjugate estrogen, produced by the placenta, with sulfate and glucuronic acid. Estrogen hydroxylation reactions also take place in the fetus, and $16 \alpha^{-}, 16 \beta-, 6 \alpha^{-}$, and $15 \alpha^{-h y d r o x y}$ as well as 2-methoxy estrogens have been isolated. This type of study has not been possible at term. It has been hypothesized that the extensive metabolism of the three principal estrogens could serve to protect the midterm fetus from high unconjugated levels of those steroids.

The plasma concentrations of $\mathrm{E}_{1}, \mathrm{E}_{2}$, and $\mathrm{E}_{3}$ have been monitored in the mother throughout gestation using radioligand and radioimmunoassay methods [29]. Declining levels of $\mathrm{E}_{2}$ [25] reflect diminishing supply of fetal steroid precursors and provide information on fetal distress and demise. Because of the limitations of previous methodologies, information is unavailable on actual circulating levels of unconjugated or conjugated $\mathrm{E}_{1}, \mathrm{E}_{2}$, or $\mathrm{E}_{3}$ in the normal or abnormal fetus during gestation and prior to term.

\section{Umbilical Vessel Levels of Estrone and Estradiol: Nor- mals}

Two groups have reported the levels of total estrogens (i.e., conjugated plus unconjugated) in the umbilical artery and vein, and found that umbilical venous levels, coming from the placenta, were not significantly different from those in the umbilical artery coming from the fetus $[17,22]$. Klausner and Ryan [13] compared unconjugated and conjugated $\mathrm{E}_{3}$ in umbilical vein and artery in five babies, and detected no consistent arteriovenous difference in paired specimens. However, Anderson and colleagues found a rapid drop in levels of unconjugated $\mathrm{E}_{1}$ and $\mathrm{E}_{2}$ when comparing cord plasma with specimens drawn from the neonate within 1 to 3 min after parturition [1]. The latter findings are consistent with extensive metabolism of unconjugated estrogen by the neonate.

Our new data show that the placenta supplies the fetus (through the umbilical vein) with very high levels of unconjugated estrone and estradiol, the former being of the order of 200 times and the latter 100 times higher than the values in nonpregnant adult females. Despite the extensive metabolism of those estrogens known to occur in the midterm fetus [5], the levels are diminished only by approximately half in the blood returning from the fetus (i.e., umbilical arteries). The method of disposal of unconjugated estrogen presumably involves the conjugating and hydroxylating mechanisms referred to above. That the fetus shows only slight evidence of feminization; i.e., palpable breast tissue, occasional "withdrawal bleeding" during the first few postnatal days, and estrogen effect on vaginal or urethral cytology [23], is surprising. Smaller amounts of circulating estrogen are capable of producing more marked physical evidence of sexual precocity in infants and children. With idiopathic sexual precocity we find levels of $\mathrm{E}_{1}$ and $\mathrm{E}_{2}$ which are well within the range for nonpregnant adult females.

It is conceivable that a decreased number of estrogen receptors in utero could relate to the lesser re- 
sponse of the fetus and neonate to such high levels of unconjugated estrogen. Evidence in support of this concept for uterus, pituitary, and hypothalamus has been obtained in rats. The concentration of uterine estradiol binding sites increases fourfold between day 1 and 10 and then remains relatively constant through day 22 [4]. A concentration gradient between pituitary and plasma is observed after day 10 in rats [11]. In a study starting at day 5, a concentration of labeled estradiol in median eminence and hypothalamus calculated as ratio to cerebral cortex is not observed until day 20-30 [20].

Another possibility is that a binding protein circulates in the fetus and neonate which prevents estrogen from reaching receptor sites. A binding protein with high affinity and high capacity for estradiol is present in rats at day 5. The concentration of this protein decreases during maturation in that species (18). No human data are available.

An additional possibility is that competition by other steroids diminishes estradiol binding at tissue sites. Large amounts of progesterone, testosterone, and cortisol do not compete [6]. The estrogen conjugates estradiol-3-sulfate or -17-sulfate do not compete more effectively than estradiol [8]. However, both estrone and estriol reduce the accumulation of ${ }^{3} \mathrm{H}-\mathrm{E}_{2}$ in anterior pituitary, uterus, vagina, and hypothalamus (6).

Irrespective of the mechanism involved, it is of considerable interest that no latent deleterious psychoogic or physiologic effects result from exposure of the fetal central nervous system to those levels of estrogen, inasmuch as alterations of those functions in the adult are produced by exogenous estrogen administered to immature animals $[9,16]$. Significant uptake of tritiated estradiol by the female rat hypothalamus has been demonstrated as early as the 20th day of gestation (15).

\section{Maternal Levels of Estrone and Estradiol: Normals}

Our data for maternal unconjugated $\mathrm{E}_{1}$ and $\mathrm{E}_{2}$ are similar to those reported by other workers for mothers at term [24]. We suggest that the higher values of $E_{2}$ than $\mathrm{E}_{1}$ could be due to the high levels of sex steroid binding globulin in the mother [3]. This globulin has a greater affinity for $\mathrm{E}_{2}$ than $\mathrm{E}_{1}$.

Maternal and Umbilical Estrogen Levels in Anencephaly and Presumed Absence of Adrenals

In the anencephalic baby, a pituitary gland can nearly always be found, although little or no hypotha- lamic tissue is present. Therefore, these babies are deprived of hypothalamic releasing factors including corticotropin releasing factor. Despite this, we have shown that cortisol is produced in anencephaly, although at a subnormal rate [12]. Anatomically, the adrenal glands are small and lack the fetal cortex. The latter is believed to be the source of the estrogen precursors produced by the fetal adrenal, principally DHA and DHAS. Therefore, the levels of urinary estriol are low in mothers carrying anencephalic fetuses [2]. Our new data show that unconjugated $\mathrm{E}_{1}$ and $\mathrm{E}_{2}$ were also low in a mother carrying an anencephalic fetus, whereas umbilical venous and arterial steroid levels were not outside the normal range.

In the baby with presumably absent adrenals, the maternal and umbilical vessel levels of both estrogens were below the normal ranges. It is suggested that the complete lack of production of estrogen precursors by this fetus had a greater effect on those levels than that produced by understimulation of the adrenals as in anencephaly. It would be of interest to explore the effects of overstimulation of the fetal adrenals, as in congenital virilizing adrenal hyperplasia (adrenogenital syndrome).

\section{Estrone and Estradiol during First $72 \mathrm{Hr}$ of Age}

The initially very high levels of estrogens in the umbilical vessels afforded a chance to follow their disappearance over the first few days of life in neonates. Considering only the portion of the slopes between 24 and $72 \mathrm{hr}$ of age, the time required for a $50 \%$ decrease in the values for $\mathrm{E}_{1}$ and $\mathrm{E}_{2}$ were 30 and $38 \mathrm{hr}$, respectively. Others, studying mothers in the immediate postpartum period at comparable times have estimated a $50 \%$ disappearance rate of $\mathrm{E}_{2}$ as $6 \mathrm{hr}$ [25]. Thus, after the initial rapid decline in $\mathrm{E}_{2}$ in the mother and neonate, and considering only the latter portion of the curve, the data are consistent with the concept that the rate of disposal of the remainder of the estradiol is slower in the neonate than in the mother.

\section{Summary}

The utilization of Sephadex-LH 20 chromatography and radioimmunoassay permitted for the first time a comparison of unconjugated estrone and estradiol in paired specimens between the mother and her infant's umbilical artery and vein. The highest levels of estrone were found in the umbilical vein, whereas estradiol was highest in maternal venous blood. A normal mother and her male infant with familial absence of 
the adrenals were found to have low levels of both estrogens. Anencephaly of the fetus was associated with marked diminution of only the maternal levels of estrone and estradiol. In the normal infants, the levels of both estrogens dropped rapidly within the first few hours of life followed by a more gradual decline.

\section{References and Notes}

1. Anderson, H. A., Bojesen, E., Jensen, P. K., and Sorensen, B.: Concentrations of free oestradiol, oestrone, and oestradiol: Precursors in human cord plasma and foetal systemic venous plasma at term. Acta Endocrinol., 48: 114 (1965).

2. BeLing, C. G.: Estrogens. In: F. Fuchs and A. Klopper: Endocrinology of Pregnancy, p. 32 (Harper and Row, New York, 1971).

3. Burton, R. M., AND Westphal, U.: Steroid hormone-binding proteins in blood plasma. Metabolism, 21: 253 (1972).

4. Clank, J. H., and Gorskr, J.: Ontogeny of the estrogen receptor during early uterine development. Science, 169: 76 (1970).

5. Drczralusy, E.: Steroid synthesis and catabolism in the human fetoplacental unit. In: H. A. Waisman and G. R. Kerr: Fetal Growth and Development, p. 111 (McGraw-Hill, New York, 1970).

6. Eisenfeld, A. J., AND Axelrod, J.: Effect of steroid hormones, ovariectomy, estrogen pretreatment, sex and immaturity on the distribution of ${ }^{3} \mathrm{H}$-estradiol. Endocrinology, 79: 38 (1966).

7. Ferin, M., Zimmering, P. E., Lieberman, S., and Vande Wiele, R. L.: Inactivation of the biological effects of exogenous and endogenous estrogens by antibodies to $17 \beta$-estradiol. Endocrinology, 83: 565 (1968).

8. Fischer, J. E. ANd Eisenfeld, A. J.: Alterations in ${ }^{3} \mathrm{H}$-estradiol distribution following postcaval shunt. Surgery, 69: 655 (1971).

9. Hendricks, S. E., AND Gerall, A. A.: Effect of neonatally administered estrogen on development of male and female rats. Endocrinology, 87: 435 (1970).

10. Hotchiss, J., Atrinson, L. E., And Knobil, E.: Time course of serum estrogen and luteinizing hormone (LH) concentrations during the menstrual cycle of the rhesus monkey. Endocrinology, 89: 177 (1971).

11. Kato, J., Sugrmara, N., AND Kobayashi, T.: Changing patterns of the uptake of estradiol by the anterior hypothalamus, the median eminence, and the hypophysis in the developing rat. In: M. Hamburgh and E. J. W. Barrington: Hormones in Development, p. 689 (Appleton, Century, Croft, New York, 1971).

12. Kenny, F. M., Preeyasombat, C., Spaulding, J. S., and Migeon, C. J.: Cortisol production rate. IV. Infants born of steroidtreated mothers and of diabetic mothers. Infants with Trisomy syndrome and with anencephaly. Pediatrics, 37: 960 (1966).

13. Klausner, D. A., AND RYan, K. J.: Estriol secretion by the human term placenta. J. Clin. Endocrinol. 24: 101 (1964).

14. Klein, G., Delevie, M., And Groud, C. J. P.: Simultaneous measurement of plasma cortisol, cortisone, corticosterone, corticosterone sulfate and 11-deoxycorticosterone sulfate by competitive protein binding assays during the perinatal period. Steroids, 19: 275 (1972).

15. Kulin, H. E., AND ReIter, E. O.: Ontogeny of the in vitro

Copyright @ 1973 International Pediatric Research Foundation, Inc. uptake of tritiated estradiol by the hypothalamus of the female rat. Endocrinology, 90: 1371 (1972).

16. Levine, S., ANd Mullins, R.: Estrogen administered neonatally affects adult sexual behavior in male and female rats. Science, 144: 185 (1964).

17. Maner, F. D., Saffan, B. D., Wiggins, R. A., Thompson, J. D., ANd PreEdy, J. R. K.: Interrelationship of estrogen concentrations in the maternal circulation, fetal circulation and maternal urine in late pregnancy. J. Clin. Endocrinol., 23: 445 (1963).

18. Nunez, E., Sayu, L., Engelmann, F., Benassayag, C., Crepy, O., AND JAYLE, M. R.: Origine embryonnaire de la proteine serique fixant l'oestrone et l'oestradiol chez la xattc impubere. C. R. Acad. Sci. Ser. D., 273: 243 (1971).

19. Pakravan, P., Kenny, F. M., Defp, R., and Allen, A. C.: Familial congenital absence of adrenal glands; evaluation of glucocorticoid, mineralocorticoid and estrogen metabolism in the perinatal period. J. Pediat. (In press).

20. Prest, J., Rohling, S., Horsky, J., and Herzman, J.: Changes in uptake of ${ }^{3} \mathrm{H}$-estradiol by the female rat brain and pituitary from birth to sexual maturity. Endocrinology, 86: 899 (1970).

21. Rodbard, D., Bridson, W., and Rayford, P. L.: Rapid calculation of radioimmunoassay results. J. Lab. Clin. Med., 74: 770 (1969).

22. Roy, E. J.: The concentrations of estrogens in maternal and fetal blood obtained at cesarean section, and the effect of hospitalization on maternal blood ocstrogen levels. J. Obstet. Gynaecol., 69: 196 (1969).

23. SILver, H. K., AND KIRCHNER, R. L.: Cytologic study of urinary sediment in the evaluation of sex hormone production in childhood. Pediatrics, 38: 886 (1966).

24. Tulchinsky, D., Hobel, C. J., Yeager, E., and Marshall, J. R.: Plasma estrone, estradiol, estriol, progesterone and 17hydroxyprogesterone in human pregnancy. I. Normal pregnancy. Amer. J. Obstet. Gynecol., 112: 1095 (1972).

25. Tulchinski, D., and Korenman, S. G.: The plasma estradiol as an index of fetoplacental function. J. Clin. Invest., 50: 1490 (1971).

26. New England Nuclear, Boston, Mass.

27. Packard Instrument Company, Inc., Downers' Grove, Ill.

28. The following prefixes have been used to indicate substituents in the parent molecule: 2 -methoxy, $6 \alpha$-hydroxy, $15 \alpha$-hydroxy, $16 \alpha$-hydroxy, and 16-keto.

29. The authors are grateful to Drs. Egon Diczfalusy and Mortimer Levitz for the gift of other steroids produced by the fetoplacental unit, to Drs. Ferin and Vande Wiele for the gift of the estradiol antiserum, to Arnold Eisenfeld for information on estrogen receptors, to Floyd H. Taylor, Ph.D., for statistical analyses, and to Lois $R$. Pischke for valuable secretarial assistance.

30. This work was presented in part at the annual mceting of the Society for Pediatric Research, May 25, 1972, and was abstracted in Pediat. Res., 6: 349/89, 1972.

31. Dr. Angsusingha was a Renziehausen Fellow.

32. This research was supported in part by Public Health Service Research Grants nos. FR 05507, FR 05416, and the Renziehausen Fund.

33. Requests for reprints should be addressed to: Frederic M. KeNny, M.D., Children's Hospital of Pittsburgh, 125 DeSoto Street, Pittsburgh, Penn. 15213 (USA).

34. Accepted for publication May 30, 1973. 